\title{
RESEARCH ARTICLE \\ Dissipation of the herbicide active ingredient glyphosate in natural water samples in the presence of biofilms
}

\author{
Szandra Klátyik ${ }^{a *}$, Eszter Takács ${ }^{a}$, Mária Mörtl $^{a}$, Angéla Földi ${ }^{b}$, Zsuzsa Trábert $^{b}$, Éva \\ Ács ${ }^{\mathrm{b}}$, Béla Darvas ${ }^{a}$ and András Székács ${ }^{a}$ \\ ${ }^{a}$ Agro-Environmental Research Institute, National Agricultural Research and \\ Innovation Centre, Budapest, Hungary; ${ }^{b}$ MTA Centre for Ecological Research, Danube \\ Research Institute, Budapest, Hungary
}

\begin{abstract}
Dissipation of the herbicide active ingredient glyphosate by microbial communities and by physical sorption on the surface of biofilms and solid particles in water was investigated in natural waters in Hungary. To assess combined effects, glyphosate was applied in its pure form (glyphosate isopropylammonium salt) and in preparation Roundup Classic ${ }^{\circledR}$ formulated with polyethoxylated tallowamines (POEA). Standing and running surface water samples were originated from Lake Balaton and River Danube between early May and mid-June of 2015. Natural biofilms, grown on glass substrates fixed to AKK-1 type carrier buoy, were obtained from the same locations. The kinetics of dissipation of glyphosate was investigated for 5 weeks, under controlled laboratory conditions in aquaria containing natural water $(15 \mathrm{~L})$, with or without the presence of mostly algal biofilms, with water exchange from the original locations every week. The concentration of glyphosate was measured, upon chemical derivatisation with 9-fluorenylmethyloxycarbonyl chloride and solid phase extraction, by high-performance liquid chromatography combined with UV-VIS absorbance detection or tandem mass spectrometry. The quantity and the biofilm structure of algal biomass upon exposure to pure or formulated glyphosate was determined by in vivo fluorimetry and by scanning electron microscopy. The presence of POEA affected the dissipation of glyphosate, and dissipation profiles also differed in the investigated natural water samples with or without the presence of biofilms. The results indicate that glyphosate is capable to modify the structure of the algal community and to induce increased secretion of extracellular polymeric substances matrix in the biofilms assessed.
\end{abstract}

Keywords: glyphosate; dissipation; biofilm; Roundup Classic; POEA

Correspondence author: Szandra Klátyik, tel.: +36 709311456 , e-mail address: sz.klatyik@cfri.hu

E-mail addresses of all Authors:

Szandra Klátyik_sz.klatyik@cfri.hu

Eszter Takács e.takacs@cfri.hu

Mária Mörtl_m.mortl@cfri.hu

Angéla Földi foldi.angela@okologia.mta.hu

Zsuzsa Trábert_trabert.zsuzsa@okologia.mta.hu

Éva Ács

acs.eva@okologia.mta.hu

Béla Darvas

b.darvas@cfri.hu

András Székács

a.szekacs@cfri.hu

\section{Introduction}

Various pesticide active ingredients and formulations used in intensive agriculture exert high direct or mediated impact on the environment, especially in surface waters via their leaching, drifting, surface run-off from treated sites, foliar spray and unintended overspray and may pose hazards to the drinking water bases as well $[1,2]$. The appearance of the worldwide used active ingredient glyphosate in surface water is a globally observed 
phenomenon because of its good solubility in water and widespread use. The water solubility of glyphosate is $11.6 \mathrm{~g} \mathrm{~L}^{-1}\left(25^{\circ} \mathrm{C}\right)$, while degradation half-life (DT 50$)$ in water is between 28 and 91 days (photodegradation excluded) [3]. Significant differences were detected in glyphosate contamination all over the world. Although several studies report levels of contamination at about $0.01 \mu \mathrm{g} \mathrm{L}^{-1}$, i.e. near to the limit of detection (LOD) [4,5], the average contamination level in surface water has been found between 100-200 $\mu \mathrm{g} \mathrm{L}^{-1}[6,7]$, and actual levels can reach up to $5200 \mu \mathrm{g} \mathrm{L}^{-1}$ [8] in regions, where the use of glyphosate-based pesticide formulations is substantial due to the cultivation of genetically modified glyphosate-resistant crops. The concentrations of glyphosate in surface waters in the European Union (EU) is between 0.05 and $4.7 \mu \mathrm{g} \mathrm{L}^{-1}$ as reported in several studies $[4,9,10]$. In the United States of America (USA), the accepted maximum level of for glyphosate residues in drinking water is $700 \mu \mathrm{g} \mathrm{L}^{-1}$ [11], while $0.1 \mu \mathrm{g} \mathrm{L}^{-1}$ in the EU [12]. The acceptable maximum level of glyphosate (among all pesticide residues) is $1.0 \mu \mathrm{g} \mathrm{L}^{-}$ ${ }^{1}$ in the EU [13].

The half-life of glyphosate in environmental matrices is strongly influenced by factors such as microbial activity. Glyphosate is rapidly adsorbed onto sediment particles depending on the metal content of the sediment phase, and is gradually degraded into its main metabolite, aminomethylphosphonic acid (AMPA). After 28 day post treatment glyphosate and AMPA were detectable in surface water samples derived from an estuarine pond, in contrast to the sediment samples, which did not contain the investigated compounds [14].

Various co-formulants and additives used in pesticide formulations have traditionally been considered as inactive/inert ingredients in pesticide formulations. However, these substances are deliberately applied to modify the physical/chemical characteristics of the active ingredient(s) in formulations, and several studies confirmed, that the formulating agents, particularly polyethoxylated tallowamines (POEA), a complex combination of homologs of different aliphatic moieties and ranges of ethoxylate units [15], exert their own toxicity or affect the toxicity of the active ingredients [16,17]. Therefore, comparative studies among pure active ingredients and their formulated products are of increasing importance.

Biofilm development on natural or artificial solid surfaces in water media play a particularly important role in the biogeochemical cycles, dynamics of the aquatic ecosystems and biodegradation of pollutants in natural waters [18,19]. Biofilms are compact communities of photoautotrophic (algae) and heterotrophic microorganisms (bacteria, fungi, protozoa) embedded in their extracellular polymeric substance (EPS) secretions [20]. EPS consists of proteins, polysaccharides, lipids, lectins, nucleic acids, etc., and can serves as sorption sites [21]. The EPS matrix is a dynamic system, responsible for the structure and morphology of the biofilms by filling and forming the space between the algal cells [22]. The structure of the EPS matrix is significantly stronger in the presence of various cations resulting in interactions with exposed carboxyl groups on the EPS, formation of macromolecule networks, and increased viscosity or gelation. The EPS matrix plays an important role in the protection of microbes against physical-chemical stresses [23] and the sorption of toxic organic contaminants (e.g. chlorophenols and polyaromatic hydrocarbons [24], atrazine, diclofop-methyl [25] or organic pollutants BTX [26]), and additionally it concentrates nutrients [27]. Increased production and secretion of the EPS matrix can be interpreted as stress responses of the biofilms to different adverse effects [28,29]. Accumulation of various metal ions (e.g. $\left.\mathrm{Cd}^{2+}, \mathrm{Cr}^{3+}, \mathrm{Cu}^{2+}\right)$ by biofilms has been confirmed [30]: the sorption capacity of the biofilms can be attributed to chelate or complex formation of the EPS matrix with various cations, and the uptake of cations by bacteria and alga species in biofilms. Furthermore, 
the binding capacity of the EPS matrix is significantly influenced by the $\mathrm{pH}$ of the water and its physical stage (dissolved, slime or gel state) [31]. Biofilms are widely used for monitoring studies, due to their sessile way of life; their rapid response to environmental changes (because of their short life cycle); their microbial community consist of high number of species with different sensitivity for various environmental effects; and the easy way of sampling it [32,33]. The EPS matrix can trap nutrients from water for the microorganisms in biofilms [34], and present a highly reactive surface area for sorption and metabolism of chemical compounds [25]. In turn, biofilms can take part in the adsorption, biodegradation and decomposition of the contaminants [35].

The aim of this study was to investigate and compare the dissipation of glyphosate in pure and formulated forms in freshwater samples originated from Lake Balaton and River Danube, with and without the presence of natural freshwater biofilms. Dissipation was investigated as the biodegradation of glyphosate by microbial activities and physical sorption on the surface of biofilms and solid particles of water samples.

\section{Experimental}

\subsection{Standards and reagents}

Glyphosate isopropylammonium (IPA) salt was received from Lamberti SpA (Albizzate, Italy). Herbicide formulation Roundup Classic ${ }^{\circledR}$ (Monsanto Europe S.A./N.V.) [36] was purchased from public commercial source. The main chemical characteristics of the selected active ingredient, glyphosate-based herbicide and the surfactant POEA used in Roundup Classic ${ }^{\circledR}$ can be found in Table 1. According to its Material Safety Data Sheet (MSDS), Roundup Classic ${ }^{\circledR}$ contains $41.5 \%$ glyphosate IPA salt and 15.5\% POEA, both ingredients unequivocally identified by their Chemical Abstracts Service (CAS) Registry Numbers (see Table 1). The authorization of Roundup Classic ${ }^{\circledR}$, formulated by Monsanto Europe S.A. was cancelled its POEA content (see its MSDS) in Hungary at December 2016 [36,37]. All other chemicals, including analytical standards of glyphosate, derivatising agent 9-fluorenylmethyl chloroformate (FMOC-Cl), organic solvents acetonitrile (ACN), methanol $(\mathrm{MeOH})$, dichloromethane, as well as phosphate and borate buffers, aqueous formic acid and ammonium acetate for HPLC analyses and glutaraldehyde for fixation for scanning electron microscopy were obtained from SigmaAldrich Co. LLC (St. Louis, MO, USA). Analytical standards were $\geq 97.5 \%$ purity. Solid phase extraction was carried out using Strata-X Polymeric SPE cartridge (Phenomenex, Torrance, USA) (volume of $3 \mathrm{~mL}, 200 \mathrm{mg}$ sorbent).

\subsection{Experimental setup}

\subsubsection{Determination of dissipation in natural water samples}

Dissipation of glyphosate active ingredient was investigated in its pure (glyphosate IPA salt) and formulated form (Roundup Classic ${ }^{\circledR}$ herbicide formulation) in surface waters of two origins. Freshwater samples were originated from Lake Balaton (Tihany Bay 46.914190, 17.892916, Tihany, Hungary), the largest standing water body in Europe and River Danube (Green Island - 47.481641, 19.057645, Budapest, Hungary) the second longest, navigable river of Europe. Water quality of the collected samples was characterised by $\mathrm{pH}$ of 8.4-5.54 and 8.1-8.2, and conductivity of 650-700 and 715-755 $\mu \mathrm{S} \mathrm{cm}{ }^{-1}$ for Lake Balaton and River Danube, respectively. The kinetics of dissipation investigated under laboratory conditions in aquaria containing natural water $(15 \mathrm{~L})$ with water exchange every week. During the experiments, the water in the aquaria was slowly stirred (to assure oxygen dissolution), temperature-controlled $\left(22 \pm 2^{\circ} \mathrm{C}\right)$ and illuminated 
154 (L:D = 15:9, daily light program 6-9 hrs $5.4 \mu \mathrm{mol} \mathrm{m}^{-2} \mathrm{~s}^{-1}$ (photosynthetically active 155 radiation, PAR) (400 lux), 9-18 hrs $13.5 \mu \mathrm{mol} \mathrm{m}^{-2} \mathrm{~s}^{-1}$ (PAR) (2000 lux), 18-21 hrs 5.4 $156 \mu \mathrm{mol} \mathrm{m} \mathrm{m}^{-2} \mathrm{~s}^{-1}$ (PAR) (400 lux); XiLong White $\mathrm{T} 8^{\circledR}$ ). Illuminance (lux) was determined by 157 Light Meter MS-86 (Dostmann, Wertheim-Reicholzheim, Germany), PAR was 158 determined by Coherent ${ }^{\circledR}$ Field Max (Edmund Optics, Barrington, NJ, USA). For spiking, 159 pure glyphosate IPA salt and POEA-formulated glyphosate (Roundup Classic ${ }^{\circledR}$ ) were 160 added to the aquaria containing original natural water samples, resulting in an initial glyphosate concentration of $100 \mu \mathrm{g} \mathrm{L}^{-1}$ of the glyphosate IPA salt (equivalent to $74.1 \mu \mathrm{g}$ $\mathrm{L}^{-1}$ glyphosate acid), corresponding to the lower range of average contamination levels reported in surface waters $[6,7]$.

\subsubsection{Determination of dissipation in presence of biofilms}

To determinate the dissipation in the presence of biofilms, natural biofilms were grown on glass substrates (plates of dimensions: $23 \mathrm{~cm} \mathrm{x} 9 \mathrm{~cm}$, thickness: $3 \mathrm{~mm}$, one side smooth (untreated) and one side sand blasted) fixed on AKK-1 (originated from Cséffán, Darvas \& Pasaréti) type carrier buoys immersed for 6 weeks in Lake Balaton and River Danube placed at the same location, where water sampling was regularly performed later (described above) between early May and mid-June of 2015. Prior to the outplacement of the carrier buoys, the orientation and intensity of waves, and the possibilities for protection and the reach of the location were assessed. The AKK-1 buoy includes four algal deposition rack units (containing no any metal or plastic elements) with 5 glass plates in each unit, vertically submerged into the water (at a depth of 20-30 cm). After a 6-week colonization period, the glass substrates were placed into glass aquaria (without any plastic elements) under laboratory conditions. Each aquarium contained $15 \mathrm{~L}$ water from the original location of the buoy, and water parameters $\left(22 \pm 2{ }^{\circ} \mathrm{C}, \mathrm{L}: \mathrm{D}=15: 9\right.$, stirring) were controlled. Five biofilm substrates with sand blasted and smooth surface sides were placed into each aquarium (the sixth substrate was used for further analytical and microscopic evaluations). Control units in aquaria without glyphosate (pure or formulated) treatment were applied during the experiments. The algal deposition units were placed in the same position, and the order of the substrates was not modified in the aquaria. The water in the aquaria was changed weekly, with water of original locations, where the biofilm had been developed. The dissipation was investigated in case of both glyphosate forms (formulated and pure active ingredient), and identical initial glyphosate concentrations (100 $\mu \mathrm{g} \mathrm{L}^{-1}$ of glyphosate IPA salt, equivalent to $74.1 \mu \mathrm{g} \mathrm{L}^{-1}$ glyphosate acid) were applied at the beginning of the experiments and upon each weekly water exchange.

\subsection{Analytical methods}

192

\subsubsection{Sampling}

Dissipation of glyphosate was determined daily in freshwater samples originated from 195 Lake Balaton and River Danube, therefore $15 \mathrm{~mL}$ water sample was collected every day 196 from each aquarium during the experiment. In the presence of biofilms, dissipation was 197 investigated on the basis of sample collection performed daily during the first week (the 198 first sample taken in 30 minutes after glyphosate application), and weekly during each 199 further water exchange. The samples were frozen at $-24^{\circ} \mathrm{C}$ until sample preparation and 200 measurement [38,39].

\subsubsection{Sample preparation}


Water samples $(5 \mathrm{~mL})$ were derivatised with $250 \mu \mathrm{L}$ of FMOC-Cl $(0.5 \mathrm{mM})$ and $0.3 \mathrm{ml}$ of borate buffer ( $\mathrm{pH} 9$ ) [40]. Upon 1 min of vigorous shaking, the solution was incubated at room temperature for 1 hour. The excess amount of $\mathrm{FMOC}-\mathrm{Cl}$ was removed by extracting the reaction mixture three times, each with $1 \mathrm{ml}$ of dichloromethane. The aqueous phase separated was subjected to solid phase extraction (SPE) to concentrate the samples for HPLC-UV analysis [41]. Cartridges (Strata-X sorbent, $33 \mu \mathrm{m}, 200 \mathrm{mg}$; Phenomenex, Torrance, USA) were conditioned by the addition of $5 \mathrm{~mL}$ of $\mathrm{MeOH}$, then $5 \mathrm{~mL}$ of distilled water, and finally $5 \mathrm{~mL}$ of phosphate buffer $(\mathrm{pH}=3)$. Subsequently, the derivatised water samples $(5 \mathrm{~mL})$ were added, the cartridges were washed with $3 \mathrm{~mL}$ of distilled water, and were air-dried. The analytes were eluted with $3.5 \mathrm{~mL}$ of methanol, the eluate was evaporated and redissolved in $0.5 \mathrm{~mL}$ of the initial eluent of the HPLC analysis, and was filtered through a $0.45 \mu \mathrm{m}$ hydrophilic polytetrafluoroethylene syringe filter (FilterBio PFTE-L) purchased from Labex Ltd. (Budapest, Hungary). Derivatised samples were not subjected to SPE prior to LC-MS/MS measurements.

\subsubsection{Analytical determination}

Glyphosate concentration of water samples was analysed by HPLC-UV using an optimised analytical method reported elsewhere with fluorescent detection $[40,42]$. Negative samples in HPLC-UV (under LOD: $5 \mu \mathrm{g} \mathrm{L}^{-1}$ ) were further analysed by LCMS/MS. HPLC-UV analyses of the investigated compounds were performed on a Younglin YL9100 ${ }^{\circledR}$ HPLC system equipped with an YL9150 autosampler. Glyphosate were separated on a Chromegabond WR C18 column $(150 \mathrm{~mm} \times 4.6 \mathrm{~mm}$, i.d. $3 \mu \mathrm{m})(\mathrm{ES}$ Industries, Berlin, Germany) at $40^{\circ} \mathrm{C}$. UV detector signals were recorded at $\lambda=260 \mathrm{~nm}$. External calibration was based on the results obtained for 7 standard solutions in the range of concentrations between 5 and $150 \mu \mathrm{g} \mathrm{L}^{-1}$. Calibration solutions were prepared from a stock solution by dilution with acetonitrile:buffer $(10 \mathrm{mM}$ ammonium acetate in water, $\mathrm{pH}=6.0$ ). The eluent flow rate was $0.7 \mathrm{~mL} \mathrm{~min}^{-1}$ with gradient elution. Initial eluent (1:9 $=\mathrm{A}: \mathrm{B}$ eluents, $\mathrm{A}=100 \%$ acetonitrile, $\mathrm{B}=10 \mathrm{mM}$ sodium acetate buffer water) was increased to $90 \% \mathrm{~A}$ at $6 \mathrm{~min}$, maintained for $3 \mathrm{~min}$, and then returned to initial composition in a min and equilibrated for $3 \mathrm{~min}$. The injection volume was $30 \mu \mathrm{L}$.

Water samples with glyphosate content below the $\operatorname{LOD}\left(5 \mu \mathrm{g} \mathrm{L}^{-1}\right)$ were subjected to liquid chromatography-tandem mass spectrometry (LC-MS/MS) [39,41] on a ThermoFinnigan TSQ-20003 Quantum Discovery MAX (Thermo Electron Corp., San Jose, USA) liquid chromatograph (LC) equipped with a triple quadrupole mass spectrometer with electrospray ionization (ESI). Compounds were separated on a Kinetex XB-C18 column $(2.1 \mathrm{~mm} \times 100 \mathrm{~mm}$, i.d. $5 \mu \mathrm{m})$ (Phenomenex, Torrance, CA, USA, purchased from Gen-Lab Ltd, Budapest, Hungary) at $25^{\circ} \mathrm{C}$. Gradient elution was conducted with at flow rate of $0.2 \mathrm{~mL} \mathrm{~min}^{-1}$. Aqueous formic acid $(0.1 \%$, eluent A) and acetonitrile (eluent B) were used as eluents. Prior to the measurements, both eluents were filtered through regenerated cellulose filters $(0.2 \mu \mathrm{m})$. The composition of the eluents was changed in time as follows: $0 \min 3 \% \mathrm{~B}, 2 \min 3 \% \mathrm{~B}, 10 \min 50 \% \mathrm{~B}, 15 \min 3 \% \mathrm{~B}, 25 \min 3 \% \mathrm{~B}$. Experiments were conducted in positive and negative ionization modes. The LOD of the method was $1 \mathrm{ng} \mathrm{L}{ }^{-1}$.

\subsection{Biological experiments}

\subsubsection{Sampling procedure}

Prior to the location of the AKK-1 carrier buoy and 6-week biofilm colonization period $1 \mathrm{~cm} \times 1 \mathrm{~cm}$ sand blasted glass plates were fixed on the biofilm glass substrates, and the developed biofilms were used for the electron microscopic examination of the biofilms. 
The collection of the biofilm samples were performed after completion of the biofilm development period and at the end of the experiment.

\subsubsection{Sample preparation}

Biofilm samples were fixed prior to the scanning electron microscopy (SEM). During the fixation of the biofilm samples using $10 \mathrm{~mL}$ of $5 \%$ glutaraldehyde solution for 3 hours at room temperature $\left(20^{\circ} \mathrm{C}\right)$, followed by two washing steps using $10 \mathrm{~mL}$ of $0.2 \mathrm{M}$ phosphate buffer for $10 \mathrm{~min}$. The fixed biofilm samples were stored at $-80{ }^{\circ} \mathrm{C}$ until lyophilisation performed by Christ Alpha 1-4 LSC ${ }^{\circledR}$ (Osterode, Germany). During lyophilisation, the duration of the main freeze-drying was 20 hours $\left(1.025 \mathrm{mbar},-56{ }^{\circ} \mathrm{C}\right)$ followed by 4-hour final drying $\left(0.825 \mathrm{mbar},-56^{\circ} \mathrm{C}\right)$ [43]. The lyophilised samples were fixed onto a stub using double-sided carbon tape followed by coating with gold by a rotary-pumped spatter coater (Quorum Q150 R $S^{\circledR}$, London, England).

\subsubsection{Biological determination}

The effects of active ingredient glyphosate and formulation Roundup Classic ${ }^{\circledR}$ on algal biomass of biofilms were determined with bbe Moldaenke BenthoTorch ${ }^{\circledR}$ (Schwentinental, Germany) algae torch instrument based on real-time measurement of benthic algal concentrations by in situ quantification of chlorophyll-a fluorescence and in vivo fluorescence of algal cells. During the measurement, algal cells are excited by LEDs at different wavelengths and emit red fluorescence light. The algal biomass is calculated, on the basis of the quantity of chlorophyll-a content of different algae, using the intensity of chlorophyll fluorescence. The concentration of different algae was expressed in the unit of $\mu \mathrm{g}$ chlorophyll-a $\mathrm{cm}^{-2}$. The measuring range of the instrument is $0-15 \mu \mathrm{g}$ chlorophyll-a cm${ }^{-2}$ [44]. However according to Kahlert and McKie, the use of BentoTorch ${ }^{\circledR}$ for determination of the relative contribution of different algal group to benthic algal biomass is recommended only with cautious evaluation [45]. To assess the accuracy of the algal biomass determination, chlorophyll-a content was determined from the biofilm using the corresponding standardised protocol [46], and the two methods (spectrophotometric and in situ fluorometric determination of chlorophyll-a) were compared to each other in the $1-50 \mu \mathrm{g} \mathrm{mL}^{-1}$ concentration range. Moreover, in our experiments, the results were used for comparative purposes, therefore, the rates of the three algae taxa (green algae, cyanobacteria and diatom) studied were evaluated with results from SEM considered. The composition of the algae community of biofilms and their structural transformations, as well as the intensity of EPS formation were visualised from 15 randomly selected fields of each samples by SEM performed by Zeiss EVO MA $10^{\circledR}$ scanning electron microscope operated at $10 \mathrm{kV}$ and $8.5 \mathrm{~mm}$ distance using SE detector. Changes in algal biomass in response to exposure to the chemicals studied were determined, but biomasses of untreated biofilms were also measured as negative controls in each sampling interval. Control units were incubated in aquaria under the same conditions as the treatment groups, but without glyphosate (pure or formulated) treatment. Determinations were conducted on the sand blasted and smooth surface of glass substrates as well in triplicates. On both sides of the substrate the identical sampling sites of 9.62 $\mathrm{cm}^{-2}$ were measured in every two weeks, and total and relative biomass values were calculated. Standard deviations (SD) of biomass values between the sampling sites on the individual sides, glass substrates and rack units were determined.

\subsection{Statistical analysis}

Decomposition of glyphosate in pure and formulated forms in natural waters was assessed by sampling in triplicates, and each sample subjected to chemical analysis in triplicates. 
Standard calibration for quantitative determination of glyphosate has also been carried out in triplicates at each concentration level. Experiments of exposure of biofilms to pure and formulated glyphosate were performed in quadruplicates by separately immersing five glass plates with biofilms into natural waters spiked with glyphosate or Roundup Classic $^{\circledR}$. Corresponding control experiments without treatment with glyphosate have also been carried out in quadruplicates. Algal biomass was determined on each glass plate in two spots $\left(9.62 \mathrm{~cm}^{2}\right.$ each) on each side of the plate, with even geometrical distribution along the plate and identical setup throughout the experiment in each treatment group. Thus, overall 20 parallel fluorometric determinations were carried out for each time points of each treatment. Extraction for spectrophotometric measurement of chlorophyll content was carried out in triplicates at each concentration level. Effects of various treatments were statistically evaluated by one-way ANOVA (Statistica ${ }^{\circledR}$ software, StatSoft, Tulsa, USA) followed by Tukey post hoc test for comparisons between groups ( $\mathrm{p} \leq 0.05)$.

\section{Results and discussion}

\subsection{Pesticide residue analysis in surface water}

The retention time in the HPLC separation was $6.71 \mathrm{~min}$ for glyphosate. An LOD, defined as analyte concentrations corresponding to a signal level of signal/noise ratio of 3 , of the developed HPLC-UV analytical method was $5 \mu \mathrm{g} \mathrm{L}^{-1}$. The percentage recovery at a spiking level $100 \mu \mathrm{g} \mathrm{L}^{-1}$ of the glyphosate IPA salt (equivalent to $74.1 \mu \mathrm{g} \mathrm{L}^{-1}$ glyphosate acid) was found to be $83.5 \pm 6.0 \%$ for glyphosate. Glyphosate concentrations above $5 \mu \mathrm{g}$ $\mathrm{L}^{-1}$ reported in this manuscript correspond to analyses by HPLC-UV. In the rare cases, when glyphosate concentrations fell below $5 \mu \mathrm{g} \mathrm{L}^{-1}$, water samples were analysed by LCMS/MS.

The pesticide contamination status of the natural water bodies at both sampling locations was investigated weekly during the biofilm formation and sampling periods, and no detectable amounts of glyphosate residues were found. During the colonisation period of biofilms in river Danube, metolachlor (up to $1 \mu \mathrm{g} \mathrm{L}^{-1}$ ) was detected for a longer period, and occasionally terbutylazine and dimethenamid also occurred (up to $1 \mu \mathrm{g} \mathrm{L}^{-1}$ ). In mid-July, chlorpyrifos appeared (2-4 $\left.\mu \mathrm{g} \mathrm{L}^{-1}\right)$ in the water samples until the end of the sampling period. In contrast, no pesticide residues in the water samples from Lake Balaton were detected during the colonisation period, but later the presence of chlorpyrifos (2-4 $\left.\mu \mathrm{g} \mathrm{L}^{-1}\right)$ was detected at the same concentration range as seen in river Danube.

\subsection{Effects of pure and formulated glyphosate on algal biomass and composition of biofilms}

The in situ fluorometric algae torch was found a reproducible method for the determination of chlorophyll-a content in biofilms, as the surface density of chlorophylla detected highly correlated with corresponding chlorophyll-a concentrations measured by the ISO standard method of spectrometric determination of the chlorophyll-a concentration in water quality assessment [46]. Chlorophyll-a surface densities and concentrations highly correlated $\left(\mathrm{R}^{2}=0.9996\right)$ with each other in the concentration range of $1-50 \mu \mathrm{g} \mathrm{mL}^{-1}$ of chlorophyll-a.

Due to identical geometric arrangement of the algae rack units containing 6 racks each, total production rate of biomass grown on the AKK-1 type buoy was not statistically different among rack units for Lake Balaton and River Danube, respectively. Thus, differences in glyphosate concentration among treatment groups were not due to the initial biomass, but to the condition, whether glyphosate was applied in its pure or 
formulated form. Effects in biomass production were determined on identical surface dimensions among the 6 glass substrates. Higher biomass values were measured on the edge of glass plates and on the terminal plates. Maximum relative SD (SD\%) of the average biomass content among sampling sites were $35 \%$ and $40 \%$, for Lake Balaton and River Danube, respectively. However, commeasurable biomass results, significantly not different from each other, were determined among rack units in the case of both surface water sources. Average biomass production on the 2-2 rack units (used in this dissipation experiment) after the colonization period (before treatments with two form of glyphosate) were 2.26 and $2.13 \mu \mathrm{g}$ chlorophyll-a $\mathrm{cm}^{-2}$ for River Danube and 3.21 and $3.32 \mu \mathrm{g}$ chlorophyll-a cm${ }^{-2}$ for Lake Balaton.

On-going spontaneous changes in the algal community and the structure of the biofilms from River Danube in response to the various treatments were observed by algal biomass measurement and microscopic analysis, while such alterations were not observed in the corresponding control units. Biofilms originated from River Danube continued to grow under laboratory conditions, unlike those from Lake Balaton (see below). Exposure to glyphosate alone occurred to slightly promote biomass production. This is not unreasonable, as it has been reported that glyphosate at low concentrations $(0.01$ to $5 \mathrm{mg}$ $\mathrm{P} \mathrm{L}^{-1}$ ) may serve as a source of phosphate and nutrients for certain biofilm community components [47], and/or may trigger pathways for the synthesis of metabolites and proteins $[48,49]$, which can result in increased biomass growth. At higher concentrations $\left(8 \mathrm{mg} \mathrm{L}^{-1}\right)$, however, it inhibits the colonization of algae [50]. Upon treatments with POEA-formulated glyphosate (Roundup Classic ${ }^{\circledR}$ ), the initial biomass decreased in the first 2 weeks in both surface waters. Average relative biomass values were 2.04, 2.14 and $1.50 \mu \mathrm{g}$ chlorophyll-a $\mathrm{cm}^{-2}$ for algae grown on glass substrates in River Danube for the control and the glyphosate and POEA-formulated glyphosate treatments, respectively. After 2 weeks, biomass in River Danube started to increase.

In contrast, initial biomass from Lake Balaton decreased continuously during the five-week experimental period not only under treatments with pure and POEAformulated glyphosate, but in the control experiment as well from the second week on, as indicated by in situ fluorimetry and SEM images. These biofilms were rich in small, tubebuilding, algivorous chironomid larvae; Procladius choreus, Tanypus punctipennis and Chironomus balatonicus being the most abundant at the Tihany Peninsula [51,52]. The emergence of these larvae, especially Procladius species occurred to be essential for the subsistence of the biofilms, and in cases of lacking emergence, the biofilms collapsed in the aquaria in two weeks. After the two-week incubation period, 2.65, 2.82 and $2.30 \mu \mathrm{g}$ chlorophyll-a cm $\mathrm{cm}^{-2}$ were determined for the control and the treatment groups with pure and formulated glyphosate, respectively.

SEM analysis indicated considerable changes in biofilm structure. Realignment of the biofilms was typical, and glyphosate-sensitive species were replaced by tolerant ones like filamentous green algal species (Figure 1). The realignment of biofilms and the effects of glyphosate on the microbial community structure in freshwater were observed in other studies as well [50,53]. The electron microscopic analysis also indicated increased production of the EPS matrix, relative to the corresponding negative controls, in each treatment group. Visual analysis of the ESM images suggested an intensive EPS production for exposure to POEA-formulated glyphosate. This phenomenon can be attributed to the protective mechanism of bacteria and algae to eliminate and reduce the effects of contaminants [23,28,29]. Additionally, glyphosate can affect the metabolic processes of bacteria and algae simultaneously, resulting in an enhanced production of the EPS matrix as response to physical, chemical and biological stress factors $[28,29]$ (Figure 2). 


\subsection{Dissipation of pure and formulated glyphosate in natural water samples without the presence of biofilms}

Differences were observed between pure and POEA-formulated glyphosate levels (Figure 3). Significantly higher initial concentrations were measured (30 min after the addition of $100 \mu \mathrm{g} \mathrm{L}^{-1}$ of the glyphosate IPA salt (equivalent to $74.1 \mu \mathrm{g} \mathrm{L}{ }^{-1}$ glyphosate acid) in water samples originated from River Danube for formulated glyphosate treatment due to the presence of formulating agent POEA. A possible mechanism involved in this process can be that the surfactant suppressed the physical adsorption of glyphosate on the solid-liquid surfaces (e.g. glass materials of aquaria, solid phase and floating particles in water samples) [54].

Degradation of glyphosate was not detected in water samples from Lake Balaton, the level of glyphosate stagnated at 90 and $100 \mu \mathrm{g} \mathrm{L}^{-1}$ in case of the pure and POEAformulated active ingredient, respectively. Therefore, the observed changes in concentration are likely to be due to absorption or accumulation in the tissue of the biofilm. In contrast, the concentration of glyphosate in River Danube, after an initial rapid decrease, reached a constant level approximately at the concentration of $60 \mu \mathrm{g} \mathrm{L}^{-1}$.

According to our results, the environmental fate and degradation of glyphosate can be different in various natural water matrices, as the processes may be influenced by the presence of the formulating agents, the composition of the microbial communities, and the physical and chemical parameters of the water phase $[14,55]$.

\subsection{Dissipation of pure and formulated glyphosate in the presence of biofilms}

Differences were observed between the reduction of pure and POEA-formulated glyphosate levels in the presence of biofilms. Similar effects of the formulating agent POEA on initial glyphosate concentrations (30 min after the addition of $100 \mu \mathrm{g} \mathrm{L}^{-1}$ of the glyphosate IPA salt (equivalent to $74.1 \mu \mathrm{g} \mathrm{L}^{-1}$ glyphosate acid) as described in Section 3.2 (Figures 4-7). However, the presence of the biofilm resulted in further decreases of glyphosate levels, likely due to the adsorption capacity [24-26] of the EPS matrix produced by microbial activity of the biofilms. When pure glyphosate was applied, after an immediate (within 30 minutes) steep drop, glyphosate concentration remained stagnant during the first week at 15 and $80 \mu \mathrm{g} \mathrm{L}^{-1}$ for River Danube and Lake Balaton, respectively. When applied in formulation, glyphosate concentrations decreased similarly, but less instantaneously likely due to the surfactant effect of POEA, possibly facilitating the maintenance of the active ingredient molecules in solution.

\subsubsection{River Danube}

The phytotoxic effects of glyphosate, particularly if enhanced by a formulating agent, may have contributed to the observed decrease of the algal biomass relative to the untreated control. Moreover, the gradual increase in glyphosate concentrations detected after repeated weekly addition of $100 \mu \mathrm{g} \mathrm{L}^{-1}$ of pure glyphosate IPA salt (equivalent to $74.1 \mu \mathrm{g} \mathrm{L}^{-1}$ glyphosate acid) is likely to be due to saturation of the sorption sites in the EPS matrix in the biofilm. By the fourth week, the total biomass increased, accompanied by significant decreases in glyphosate concentration, possibly due to the utilization of glyphosate from water as a nutrient by tolerant algal species (Figure 4) [34,48].

When glyphosate was applied in a formulated form, the treatment resulted in a rapid gradual decrease of the concentration of glyphosate during the first week in the presence of high biomass. The treatment resulted in a decrease in the algal biomass, relative to the untreated control, within 2 weeks. Possible factors contributing to this trend are the phytotoxic effect of the formulation and the increased production of the EPS matrix 
observed in a qualitative estimation based on the SEM images. The measured level of glyphosate was stagnant upon weekly additions of glyphosate. From the third week on, gradually increasing glyphosate concentrations were detected likely due to the saturation of the sorption sites in the EPS matrix (Figure 5). Similarly to the treatment with pure glyphosate, the algal biomass increased by the fourth week. Despite the lower bioavailability of glyphosate in water, tolerant algal species occurred utilising glyphosate as a nutrient from the EPS matrix.

\subsubsection{Lake Balaton}

Biofilms formed in Lake Balaton resulted different dissipation patterns of glyphosate than those seen for River Danube. The phytotoxic effect of glyphosate or Roundup Classic $^{\circledR}$ herbicide formulation resulted in a continuous decrease in the biomass during the five-week experimental period. Compared to the degradation without the presence of biofilms, lower concentrations of glyphosate were detected in the first week possibly attributed to chelate or complex formation with the EPS matrix [31]. After the first week during the weekly, repeated addition of pure glyphosate into the aquaria, the concentration of glyphosate stabilised at the same level as observed in the first week, but on the fifth week the concentration $\left(62.3 \mu \mathrm{g} \mathrm{L} \mathrm{L}^{-1}\right)$ of the spiked glyphosate dose was significantly reduced 30 minutes after the addition (Figure 6).

Upon treatment with POEA-formulated glyphosate, the initial decline in glyphosate concentration during the first week was less rapid as observed with pure glyphosate. Upon repeated addition of formulated glyphosate, the entire dose $\left(100 \mu \mathrm{g} \mathrm{L}^{-1}\right.$ of pure glyphosate IPA salt (equivalent to $74.1 \mu \mathrm{g} \mathrm{L}^{-1}$ glyphosate acid) applied was detected in the water samples 30 minutes after treatment until the fourth week, when the level of glyphosate detected slightly dropped $\left(86.5 \mu \mathrm{g} \mathrm{L}^{-1)}\right.$ (Figure 7). This is expected to result from an increased stress response of the algal community to the exposure to Roundup Classic ${ }^{\circledR}$, potentially resulting in an increased EPS matrix production.

\section{Conclusion}

Among studies on pesticide formulating agents only a few investigate the effects of surfactants on the environmental fate of the active ingredients. Our results demonstrate that dissipation of glyphosate can be different in various natural waters, and additionally highly depends on the presence of the formulating agents, the composition of the microbial communities exposed, as well as the physical and chemical parameters of the water phase. Dissipation profiles of given glyphosate forms were different in natural water samples investigated without or in the presence of biofilms. Worldwide detectable water contamination by glyphosate can modify the structure of the algal communities in freshwater biofilms, and may induce increased stress response in them. Tests used for authorisation and environmental risk assessment of the active ingredients and their formulations are based on $\mathrm{DT}_{50}$ values determined in distilled water under laboratory conditions. However, several data and our results suggest that a revision of the applied $\mathrm{DT}_{50}$ values and determination of habitat-specific data are needed to be used in the environmental risk assessment of the pesticide active ingredients and their formulations.

\section{Acknowledgement}

The authors thank to Péter Bohus (Lamberti SpA, Albizzate, Italy) for the sample of glyphosate IPA salt; to Gyula Pasaréti and Tamás Cséffán (Agro-Environmental Research Institute, National Agricultural Research and Innovation Centre) for their contribution in the development of the AKK-1 carrier buoy; to Prof. Gyula Záray and Pál Hofmann (Eötvös Loránd University, Green Island, Budapest, Hungary), to János Györi and Géza Dobos (Balaton Limnological Institute, Centre for Ecological Research, HAS, Tihany) for the outplacement of the buoys on River Danube and Lake Balaton, respectively; to Ottó Etler 
(C Mobil Labor Kft, Zalakomár, Hungary) for the LC-MS/MS determinations; as well as to Csilla Magor, Judit Juracsek, Balázs Magyarósy and Dániel Takács for their technical support.

\section{Disclosure statement}

No potential conflict of interest was reported by the authors.

\section{Funding}

This work was supported by the Hungarian Scientific Research Fund [OTKA K109865] and the Hungarian Ministry of Agriculture [FM AD002].

\section{References}

[1] K.R. Solomon and D.G. Thompson, J. Toxicol. Environ. Health B Crit. Rev. 6, 289 (2003). doi: 10.1080/10937400306468

[2] I. Hanke, I. Wittmer, S. Bischofberger, C. Stamm and H. Singer, Chemosphere 81, 422 (2010). doi: 10.1016/j.chemosphere.2010.06.067

[3] C. MacBean, editor, The Pesticide Manual, 16 ${ }^{\text {th }}$ Edition (The British Crop Protection Council, Brighton, 2012).

[4] J. Kjaer, P. Olsen, M. Ullum and R. Grant, J. Environ. Qual. 34, 608 (2005). doi: 10.2134/jeq2005.0608

[5] R.H. Coupe, S.J. Kalkhoff and P.D. Capel, Pest. Manag. Sci. 68, 16 (2012). doi: 10.1002/ps.2212

[6] J.C. Feng, D.G. Thompson and P.E. Reynolds, J. Agricult. Food Chem. 38, 1110 (1990). doi: 10.1021/jf00094a045

[7] P.J. Peruzzo, A.A. Porta and A.E. Ronco, Environ. Pollut. 156, 61 (2008). doi: 10.1016/j.envpol.2008.01.015

[8] W.M. Edwards, G.B. Triplett and R.M. Kramer, J. Environ. Qual. 9, 661 (1980). doi: 10.2134/jeq1980.00472425000900040024x

[9] M. Mörtl, Gy. Németh, J. Juracsek, B. Darvas, L. Kamp, F. Rubio and A. Székács, Microchem. J. 107, 143 (2013). doi: 10.1016/j.microc.2012.05.021

[10] A. Székács, M. Mörtl and B. Darvas, J. Chem., 2015, Article ID 717948 (2015). doi: $10.1155 / 2015 / 717948$

[11] United States Environmental Protection Agency (US EPA), Occurrence Estimation Methodology and Occurrence Findings Report for the Six-Year Review of Existing National Primary Drinking Water Regulations, US EPA Report No. EPA-815-R03-006, 2003.

[12] European Parliament and Council, Offic. J. Eur. Comm. L330, 32 (1998).

[13] European Parliament and Council, Offic. J. Eur. Comm. L129, 23 (1976).

[14] M.T. Tsui and L.M. Chu, Chemosphere 71, 439 (2008). doi: 10.1016/j.chemosphere.2007.10.059

[15] D. Tush, K.A. Loftin and M.T. Meyer, J. Chromatogr. A 1319, 80 (2013). doi: 10.1016/j.chroma.2013.10.032

[16] J.M. Brausch and P.N. Smith, Arch. Environ. Contamin. Toxicol. 52, 217 (2007). doi: 10.1007/s00244-006-0151-y

[17] I. Székács, Á. Fejes, Sz. Klátyik, E. Takács, D. Patkó, J. Pomóthy, M. Mörtl, R. Horváth, E. Madarász, B. Darvas and A. Székács, Internat. J. Biol., Vet. Food Engineer. 87, 213 (2014).

[18] M. Schorer and M. Eisele, Water Air Soil Pollut. 99, 651 (1997). doi: 10.1007/BF02406904

[19] G. Lear, editor, Biofilms and Bioremediation: Current Research and Emerging Technologies (Caister Academic Press, New Zealand, 2016).

[20] W.G. Characklis and K.C. Marshall, Biofilms (John Wiley \& Sons, New York, 1990). 
[21] I.W. Sutherland, Microbiology 147, 3 (2001). doi: 10.1099/00221287-147-1-3

[22] Z. Lewandowski, P. Stoodley, S. Altobelli and E. Fukushima, Water Sci. Technol. 29, Article ID 223e229. (1994).

[23] J. Wingender, T.R. Neu and H.-C. Flemming, in Microbial Extracellular Polymeric Substances. Characterization, Structure and Function, edited by J. Wingender, T.R. Neu, H.-C. Flemming (Springer, Berlin, 1999).

[24] E. Antusch, J. Sauer, C. Ripp and H.H. Hahn, Gas Wasser Abwass. 75, 1010 (1995).

[25] J.R. Lawrence, G. Kopf, J.V. Headley and T.R. Neu, Canad. J. Microbiol. 47, Article ID 634e641 (2001). doi: 10.1139/w01-061

[26] R. Spath, H.-C. Flemming and S. Wuertz, Wat. Sci. Tech. 37, 207 (1998). doi: 10.1016/s0273-1223(98)00107-3

[27] C. Freeman, P.J. Chapman, K. Gilman, M.A. Lock, B. Reynolds and H.S. Wheater, Hydrobiologia 297, 61 (1995). doi: 10.1007/BF00033502

[28] D.S. Domozych, Int. J. Plant. Sci. 168, 763 (2007).

[29] H.-C. Flemming and J. Wingender, Nat. Rev. Microbiol. 8, 623 (2010). doi: 10.1038/nrmicro2415

[30] F.G. Ferris, S. Schultze, T.C. Witten, W.S. Fyfe and T.J. Beveridge, Appl. Environ. Microb. 55, 1249 (1989).

[31] A.W. Decho, Cont. Shelf. Res. 20, 1257 (2000). doi: 10.1016/S02784343(00)00022-4

[32] P.V. McCormick and J. Cairns, J. Appl. Phycol. 6, 509 (1994). doi: $10.1007 / \mathrm{bf02182405}$

[33] M. Mages, M. Ovári, W. von Tümpling and K. Kröpfl, Anal. Bioanal. Chem. 378, 1095 (2004). doi: 10.1007/s00216-003-2291-5

[34] N. Das, L.V.G. Basak, J.A. Salam, M.E.A. Abigail, J. Microbiol. Biotechnol. Res. 2, Article ID 783e790 (2012).

[35] I. Bohuss, T. Rékasi, Sz. Szikora, K. Barkács, Gy. Záray and É. Ács, Microchem. J. 79, 201 (2005). doi: 10.1016/j.microc.2004.08.001

[36] Monsanto Europe S.A., Material Safety Data Sheet of Roundup Classic ${ }^{\circledR}$. http://www.sdslibrary.monsanto.com/Lists/MSDS\%20Library/DispForm.aspx?ID $=1203(2015) \quad$ [accessed in English version 10.06.2017]; http://www.sdslibrary.monsanto.com/MSDS\%20Datasheet/7ce97326-c83a-49838b0a-8156ffa779de/Roundup\%20Classic-9543CLPhu-hu.pdf (2015) [accessed in Hungarian version 17.06.2017]

[37] National Food Chain Safety Office (2016). Authorizations of some glyphosatebased herbicides are cancelled. (in Hungarian) http://portal.nebih.gov.hu/-/szamosglifozat-keszitmeny-engedelye-visszavonasra-kerul [accessed in 17.06.2017]

[38] H. Kylin, Chemosphere 90, 1821 (2013). doi: 10.1016/j.chemosphere.2012.09.020

[39] J.D. Byer, J. Struger, P. Klawunn, A. Todd and E. Sverko, Environ. Sci. Technol. 42, 6052 (2008). doi: 10.1021/es8005207

[40] T.V. Nedelkoska and G.K.C. Low, Anal. Chim. Act. 511, 145 (2004). doi: 10.1016/j.aca.2004.01.027

[41] I. Hanke, H. Singer and J. Hollender, Anal. Bioanal. Chem. 391, 2265 (2008). doi: $10.1007 / \mathrm{s} 00216-008-2134-5$

[42] M. Küsters and M. Gerhartz, J. Sep. Sci. 33, 1139 (2010). doi: $10.1002 /$ jssc. 200900556

[43] D. Anda, G. Büki, G. Krett, J. Makk, K. Márialigeti, A. Erőss, J. Mádl-Szőnyi and A.K. Borsodi, Acta. Microbiol. Immunol. Hung. 61, 329 (2014. doi: 10.1556/AMicr.61.2014.3.7

[44] bbe Moldaenke,

BenthoTorch

<http://www.bbe- 
moldaenke.de/en/products/chlorophyll/details/benthotorch.html> (2017) [accessed 17.06.2017].

[45] M. Kahlert and B.G. McKie, Environ. Sci. Process. Impact 16, 2627 (2014). doi: 10.1039/c4em00326h

[46] International Organization for Standardization, ISO 10260:1992 Water quality -Measurement of biochemical parameters -- Spectrometric determination of the chlorophyll-a concentration (International Organization for Standardization, Geneva, 1992), p. 6.

[47] H. Qiu, J. Geng, H. Ren, X. Xia, X. Wang and Y. Yu, J. Hazard. Mater. 248-249, 172 (2013). doi: 10.1016/j.jhazmat.2012.12.033

[48] M.A. Saxton, E.A. Morrow, R.A. Bourbonniere and S.W. Wilhelm, J. Great Lakes Res. 37, 683 (2011). doi: 10.1016/j.jglr.2011.07.004

[49] C. Wang, X. Lin, L. Li and S. Lin, PLoS One 11, e0151633 (2016). doi: 10.1371/journal.pone.0151633

[50] M.S. Vera, L. Lagomarsino, M. Sylvester, G.L. Pérez, P. Rodrígez, H. Mugni, R. Sinistro, M. Ferraro, C. Bonetto, H. Zagarese and H. Pizzaro, Ecotoxicology 19, 710 (2010). doi: 10.1007/s10646-009-0446-7

[51] A. Specziár, Ann. Limnol. - Int. J. Lim. 44, 181 (2008). doi: 10.1051/limn:2008002

[52] D. Árva, M. Tóth, H. Horváth, S.A. Nagy and A. Specziár, Hydrobiologia 742, 249 (2015). doi: 10.1007/s10750-014-1989-z

[53] G.L. Pérez, A. Torremorell, H. Mugni, P. Rodríguez, M. Solange Vera, M. do Nascimento, L. Allende, J. Bustingorry, R. Escaray, M. Ferraro, I. Izaguirre, H. Pizarro, C. Bonetto, D.P. Morris and H. Zagarese, Ecol Appl., 17, 2310 (2007). doi: 10.1890/07-0499.1

[54] L. Ming, D. Fengpei, C. Chong, L. Baoying and Z. Xihai, J. Dispersion. Sci. Techn. 37, 213 (2016). doi: 10.1080/01932691.2015.1039022

[55] L.G. Goldsborough and D.J. Brown, Environ. Toxicol. Chem. 12, 1139 (1993). doi: 10.1002/etc.5620120702 
Table 1.

637 Chemical characteristics of the selected plant protection product, active ingredient and surfactant

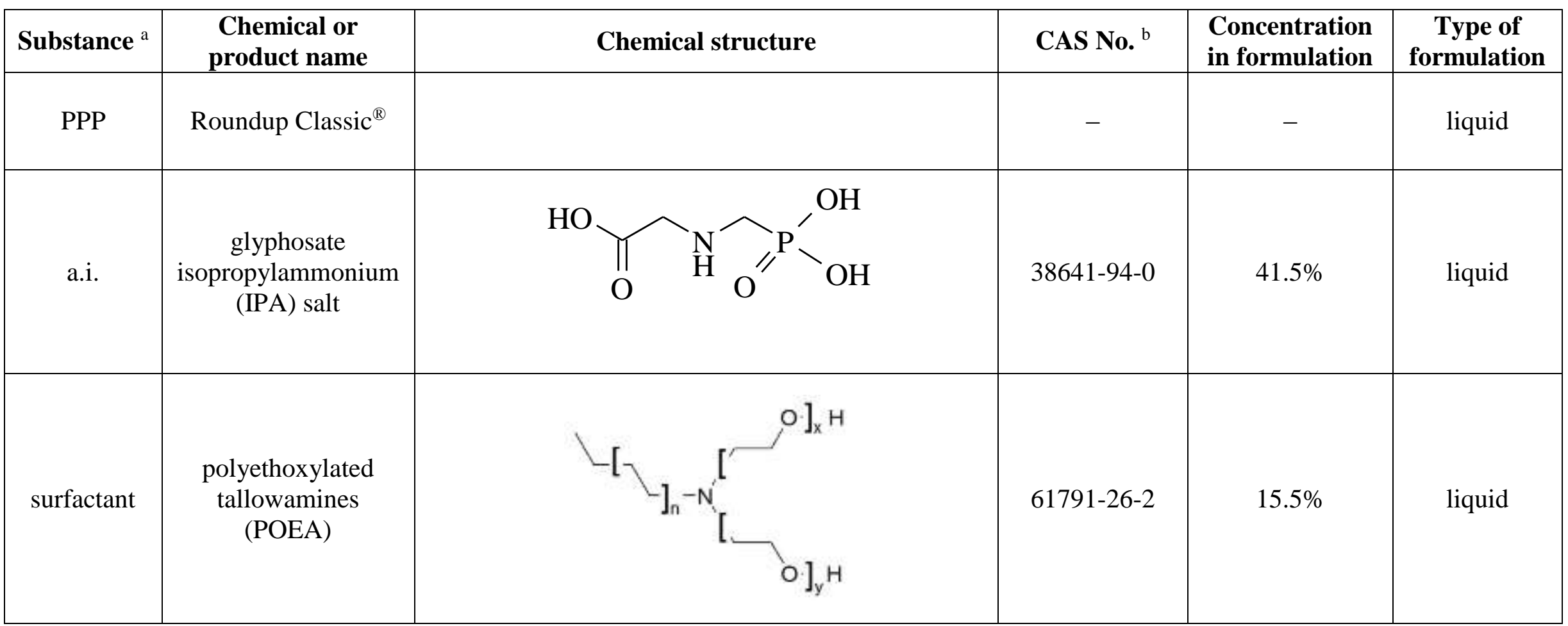

a PPP: plant protection product; a.i.: active ingredient

b CAS No.: Chemical Abstracts registry number 
Figure legends:

Figure 1. Occurrence of filamentous green algae (indicated by arrow) in natural biofilms from River Danube, due to treatment, visualised by scanning electron microscopy. A: Control biofilm without green algae (as verified by fluorimetry). B: The characteristic herbicide.

Figure 2. Increased production of EPS matrix (indicated by arrow) in natural biofilms from River Danube, due to treatment, visualised by scanning electron microscopy. A: Control biofilm with smooth EPS layer. B: Intensive EPS formation upon exposure to POEA-formulated glyphosate-based herbicide.

Figure 3 Dissipation of the IPA salt of glyphosate in pure form (hollow markers) and in preparation Roundup Classic ${ }^{\circledR}$ (filled markers) in water samples from River Danube ( $\left.\square / \mathbf{a}\right)$ and Lake Balaton $(\diamond / \diamond)$. Glyphosate concentrations were detected with HPLC-UV.

Figure 4 Dissipation of pure glyphosate ( $\square$ ) in water samples from River Danube in the presence of biofilms, depicting glyphosate concentrations ( $\square$ ) in 30 minutes after each repeated glyphosate addition $(\boldsymbol{\nabla})$. Arrows indicate concentration changes due to dissipation (solid lines) or reagent addition (dashed lines). Biomass levels in the treatment group (open black columns with solid line) and the untreated control (open grey columns with dashed line) are indicated. Corresponding algal composition (pie diagrams below each column, treatment group in the upper and control in the lower row) show the biomass proportion of cyanobacteria (dark grey), diatom (black) and green (light grey) algae.

Figure 5 Dissipation of formulated glyphosate (-) in water samples from River Danube in the presence of biofilms, depicting glyphosate concentrations ( $\square$ ) in 30 minutes after each repeated glyphosate addition $(\boldsymbol{\nabla})$. Arrows indicate concentration changes due to dissipation (solid lines) or reagent addition (dashed lines). Biomass levels in the treatment group (open black columns with solid line) and the untreated control (open grey columns with dashed line) are indicated. Corresponding algal composition (pie diagrams below each column, treatment group in the upper and control in the lower row) show the biomass proportion of cyanobacteria (dark grey), diatom (black) and green (light grey) algae.

Figure 6 Dissipation of pure glyphosate $(\diamond)$ in water samples from Lake Balaton in the presence of biofilms, depicting glyphosate concentrations ( ) in 30 minutes after each repeated glyphosate addition $(\boldsymbol{\nabla})$. Arrows indicate concentration changes due to dissipation (solid lines) or reagent addition (dashed lines). Biomass levels in the treatment group (open black columns with solid line) and the untreated control (open grey columns with dashed line) are indicated. Corresponding algal composition (pie diagrams below each column, treatment group in the upper and control in the lower row) show the biomass proportion of cyanobacteria (dark grey), diatom (black) and green (light grey) algae.

Figure 7 Dissipation of formulated glyphosate $(\downarrow)$ in water samples from Lake Balaton in the presence of biofilms, depicting glyphosate concentrations ( ) in 30 minutes after each repeated glyphosate addition $(\boldsymbol{\nabla})$. Arrows indicate concentration changes due to

*Corresponding author. Email: sz.klatyik@cfri.hu 
Sz. Klátyik et al.

694 dissipation (solid lines) or reagent addition (dashed lines). Biomass levels in the treatment 695 group (open black columns with solid line) and the untreated control (open grey columns 696 with dashed line) are indicated. Corresponding algal composition (pie diagrams below 697 each column, treatment group in the upper and control in the lower row) show the 698 biomass proportion of cyanobacteria (dark grey), diatom (black) and green (light grey) 699 algae. 
Figure 1

Figure 2
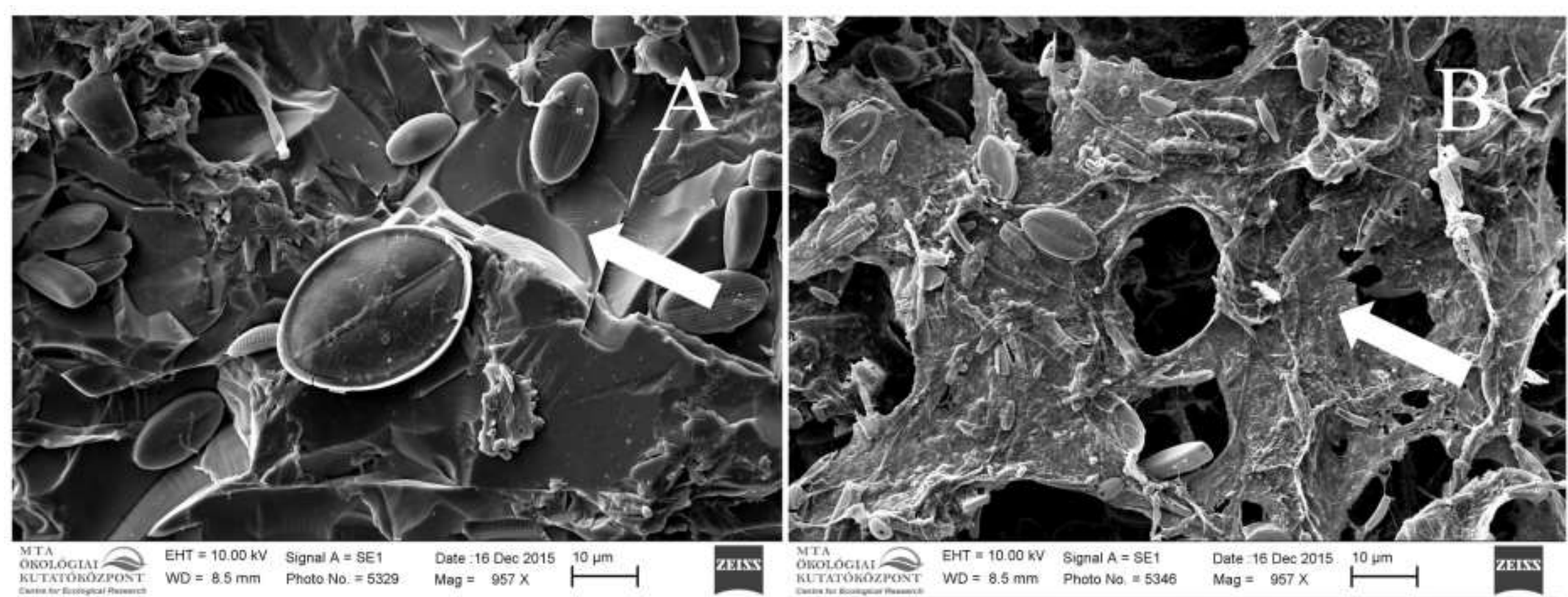
711

712

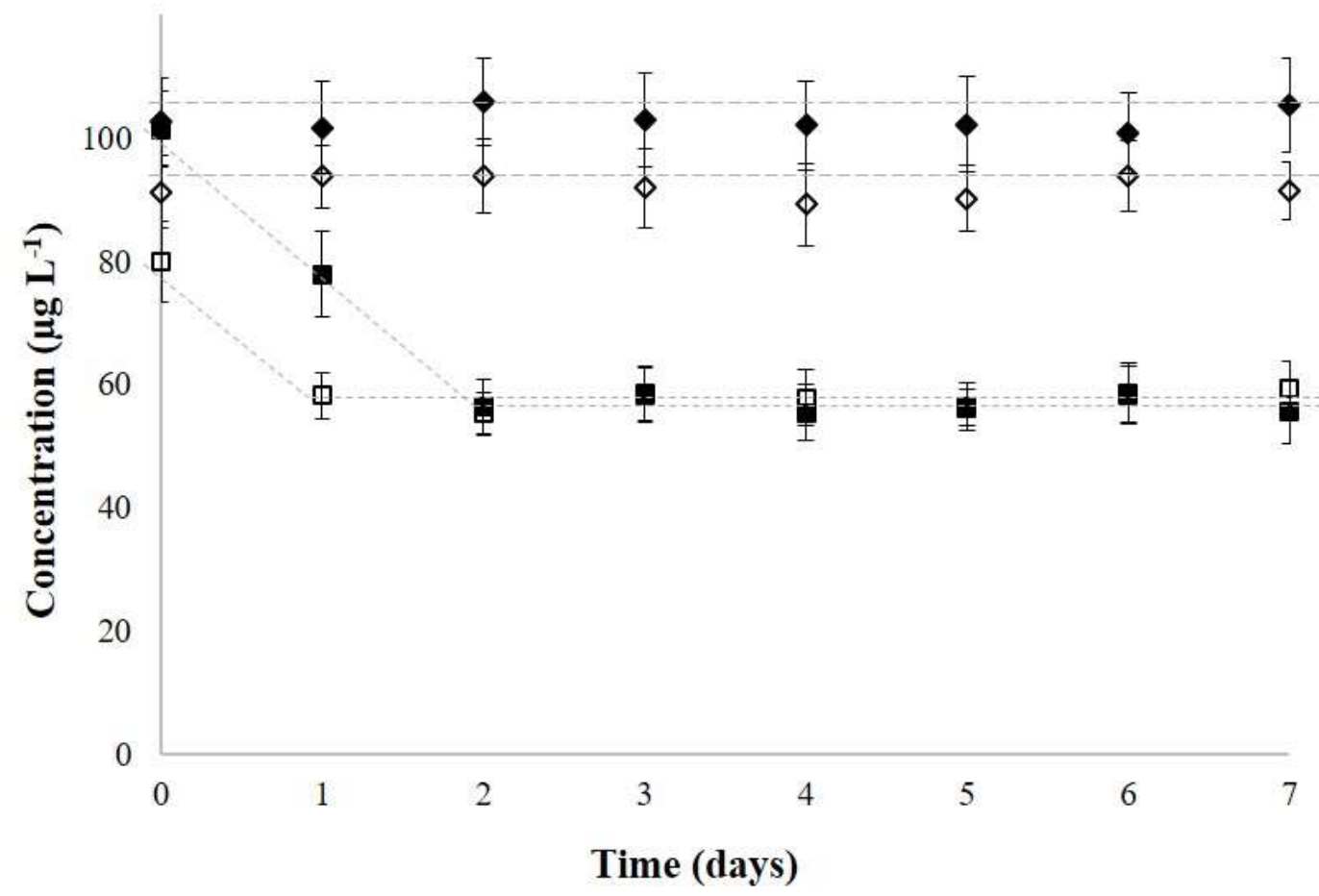


Sz. Klátyik et al.

Figure 4

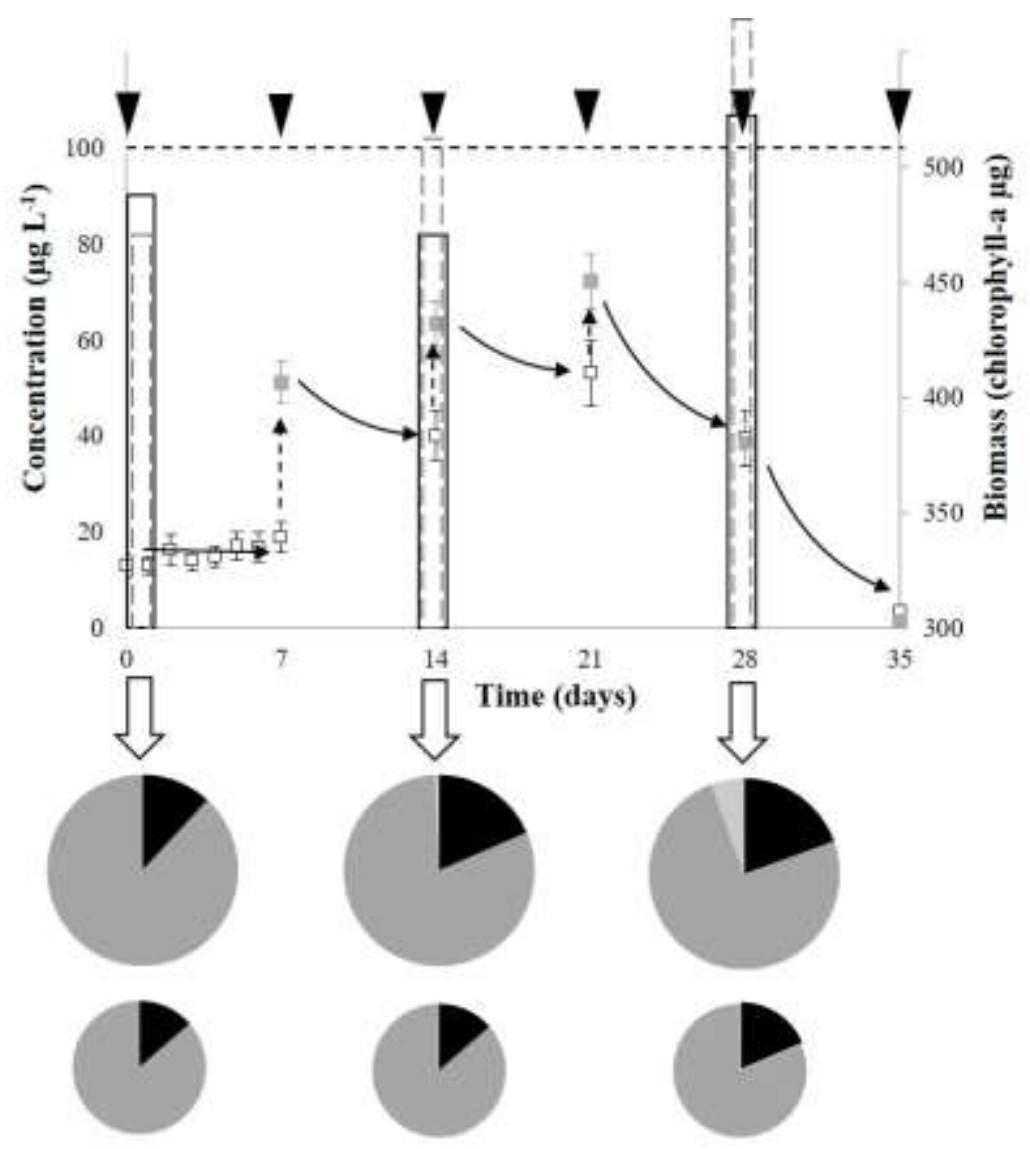


Figure 5
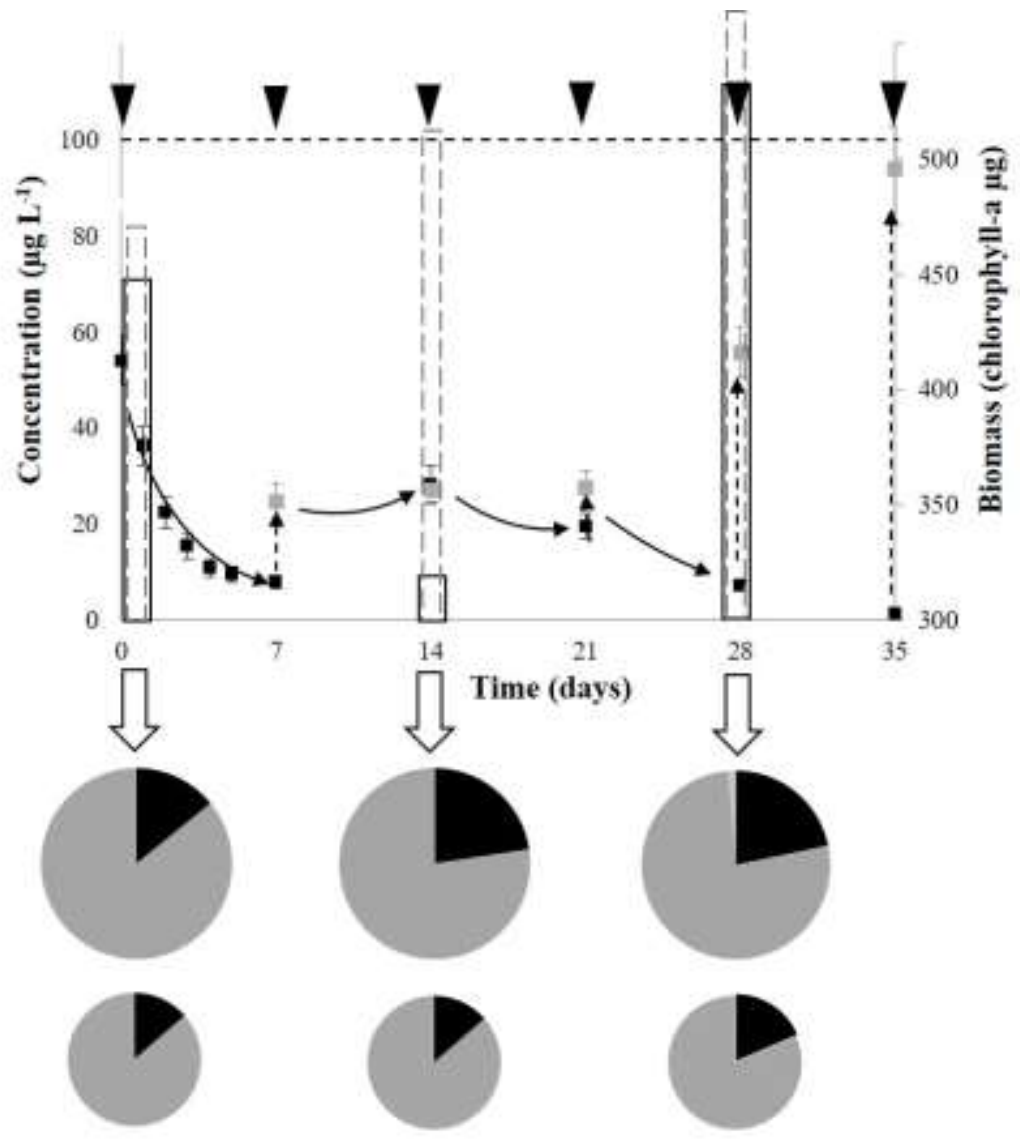
Sz. Klátyik et al.

Figure 6

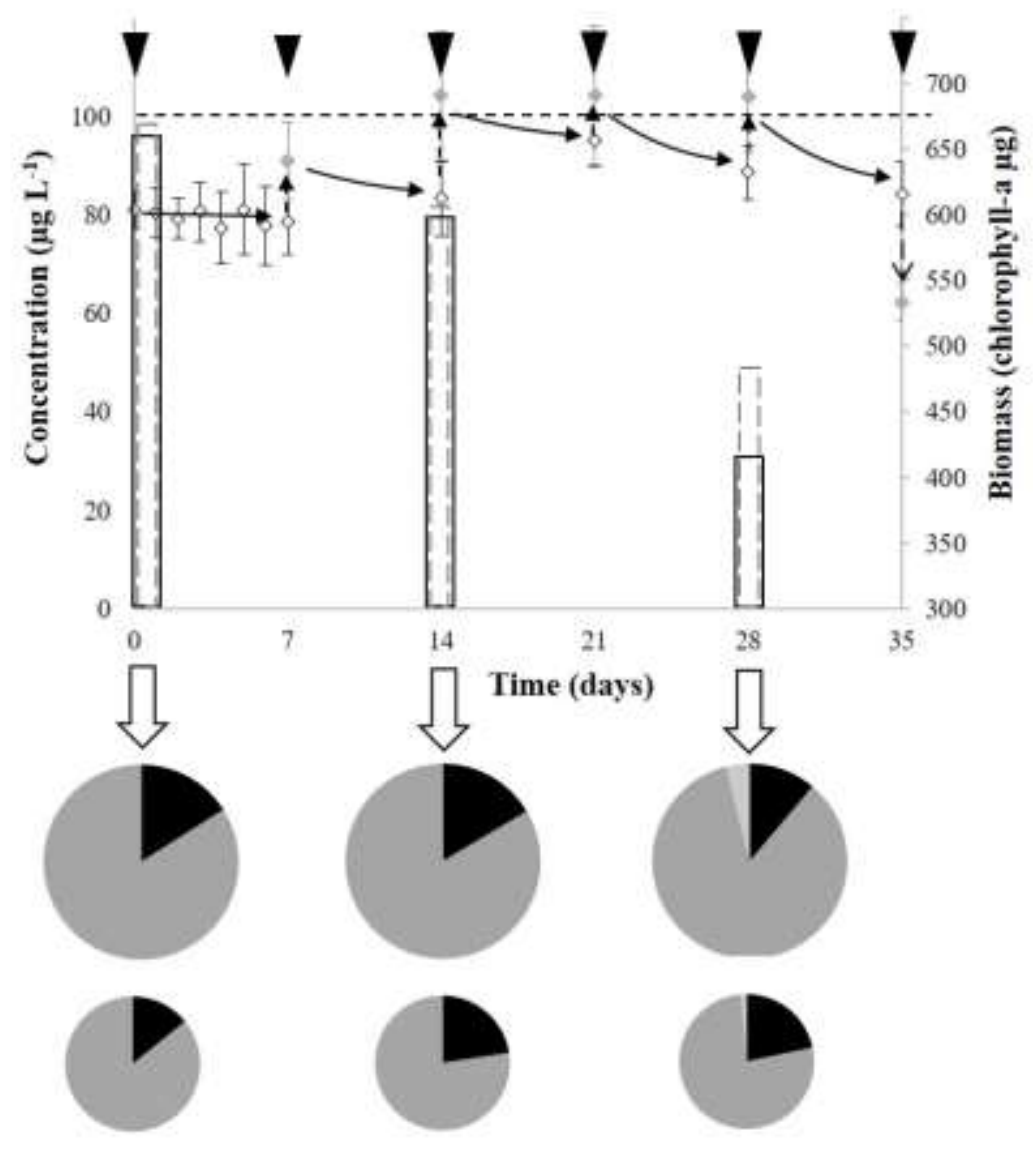


Figure 7

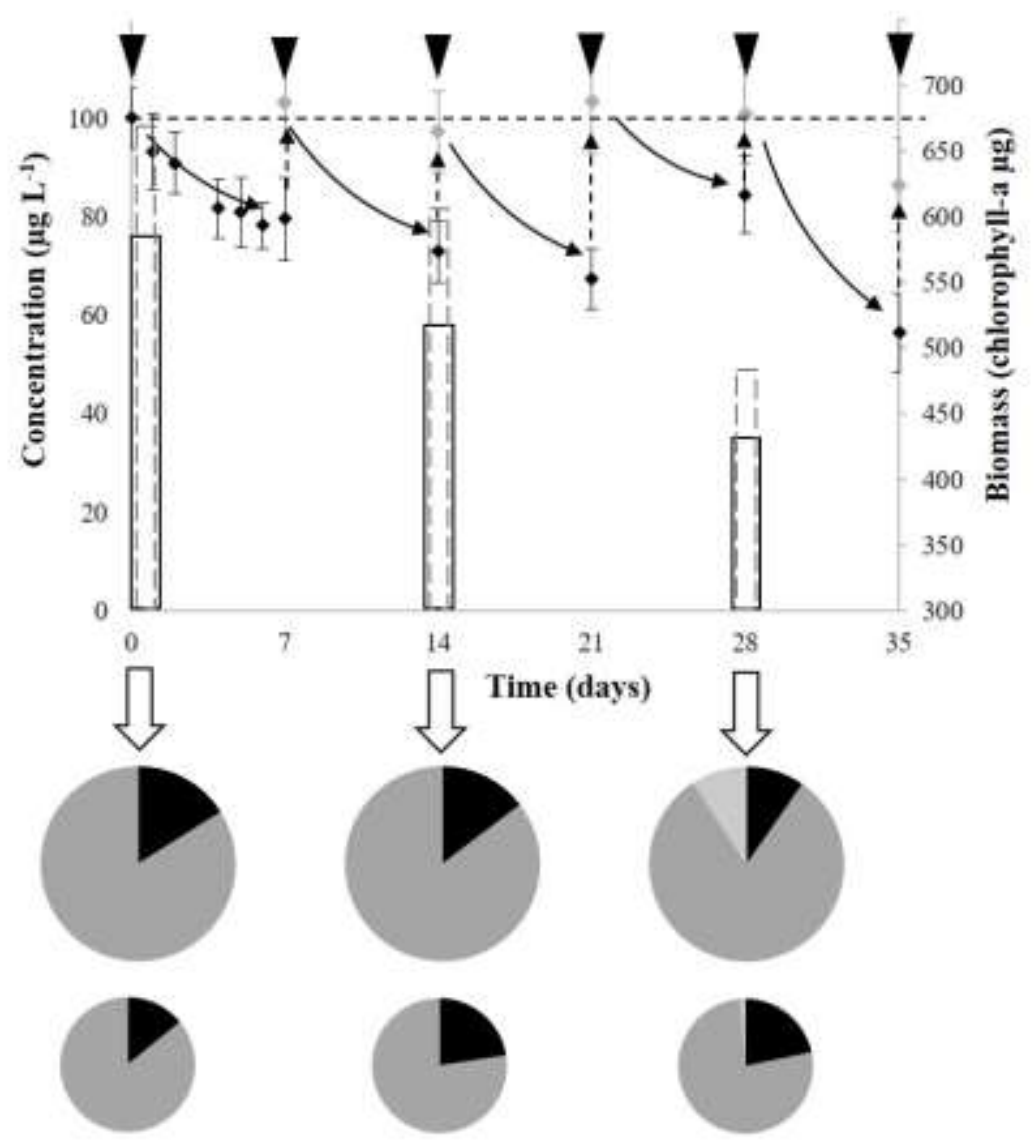

